\title{
PENGARUH TERPAAN IKLAN OBAT NON RESEP DENGAN SIKAP MASYARAKAT (Studi regresi sederhana mengenai terpaan iklan obat-obat non resep yang tayang pada televisi dengan sikap masyarakat terhadap keputusan pembelian)
}

\author{
Aat Ruchiat Nugraha \\ Dosen Prodi Hubungan Masyarakat \\ Fakultas Ilmu Komunikasi-Universitas Padjadjaran \\ Email: aatruchiat.nugraha@gmail.com \\ ruchiat@unpad.ac.id
}

\begin{abstract}
ABSTRAKS
Penemuan obat merupakan suatu keajaiban besar bagi kehidupan umat manusia. Khasiatnya yang tinggi dalam penyembuhan dan kesehatan tubuh, bahkan bisa menyelamatkan nyawa, membuat kita sedemikian rupa tergantung akan keberadaannya. Berbagai iklan obat-obat yang ditayangkan di media televisi sebagai media komunikasi yang bersifat audio-visual masih dijadikan sumber rujukan utama oleh khalayak dalam membeli dan memutuskan untuk mengkonsumsi obat-obat tersebut demi kesehatan dengan tipe penyakit termasuk kategori ringan. Penelitian ini bertujuan untuk mengetahui sejauhmana terpaan iklan di televisi terhadap sikap masyarakat dalam mengkonsumsi obat-obat non resep yang dijual bebas di pasaran. Metode penelitian yang digunakan yaitu metode kuantitatif dengan jenis studi regresi sederhana. Adapun teori yang digunakan berdasarkan teori Cognitive Response dengan populasinya adalah masyakarat kota Bandung dan teknik pengumpulan data dilakukan dengan cara menyebarkan angket terhadap responden yang terpilih melalui teknik sampling multistage cluster. Hasil penelitian menunjukkan bahwa keputusan pembelian suatu produk (obat non resep) yang dilakukan oleh masyarakat masih ada yang tergantung terhadap terpaan-terpaan iklan yang ditayangkan oleh televisi.
\end{abstract}

Kata Kunci: Obat Non Resep, Iklan, dan Televisi

\begin{abstract}
Drug discovery is a major miracle for human life. High efficacy in healing and health, can even save lives, make us so much dependent existence. Various advertising drugs that aired on television as a medium of communication that is still used as the audio-visual main reference source by audiences in buying and decided to take the drugs for the health of the types of diseases including lightweight category. This study aims to determine the extent of exposure to advertising on television on people's attitudes to consume non-prescription drugs are sold freely on the market. The research method used is quantitative method with the kind of simple regression studies. The theory is used based on the theory of Cognitive Response to the population is a society of Bandung and techniques of data collection is done by distributing questionnaires to the respondents were selected through multistage cluster sampling technique. The results showed that the decision to purchase a product (non-prescription drugs) by the community still dependent on exposure to ads served by television.
\end{abstract}

Keywords: Non-Prescription Drugs, Advertising and Television 


\section{A. PENDAHULUAN}

Memasuki era perdagangan bebas dalam masyarakat ekonomi ASEAN, pengawasan pada produk obat dan makanan perlu ditingkatkan, baik pengawasan produk sebelum beredar di pasar maupun ketika berada di pasar (postmarket). Proses sistem pengawasan ini memerlukan kemitraan dengan berbagai pihak, diantaranya ditindak-lanjuti dengan penguatan pengawasan setelah suatu barang beredar di masyarakat. Pengawasan pemerintah adalah pencegah utama terhadap iklan menyesatkan. Tanggungjawab ini dibagi oleh beberapa instansi pemerintah diantaranya BPOM, Dinas Kesehatan, dan Komisi Penyiaran Indonesia (KPI). Sedangkan dari unsur masyarakat yaitu YLKI, P3I, dan lain sebagainya. Berkaitan dengan peredaran obat non resep dimasyarakat yang begitu maraknya serta ditambah dengan kondisi pasar obat rakyat yang tidak diawasi dengan baik oleh pemerintah, akibat masih longgarnya peraturan pengawasan oleh dinas pemerintah terkait terhadap peredaran obat.

Di sisi lain, keberadaan apotik hanya terdapat pada tempat-tempat tertentu yang berdekatan dengan penyelenggaraan kegiatan kesehatan misal puskesmas atau balai pengobatan. Faktanya, masih banyak orang/ masyarakat yang suka beli obat di warung karena alasan kepraktisan tanpa menyadari akan risikonya. Obat seharusnya tidak ada di warung ataupun retailer-retailer yang berada dilingkungan pemukiman padat. Padahal, keberadaan peredaran obat non resep yang berada di warung kelontongan sangat rawan terhadap pemalsuan dan perizinan penjualan obat yang sesuai dengan standar dari BPOM. Dari sini membuktikan bahwa kalau kita beli obat non resep di channel yang resmi, akan lebih kecil risiko terpapar oleh obat palsu. Sesungguhnya industri farmasi adalah industri yang bersifat highly regulated, dalam artian pembuatan obat yang baik dilakukan dengan serangkaian metode-metode yang harus ditaati. Antara lain, menjaga konsistensi mutu, tempat yang higienis, menyerahkan hasil uji klinik, memenuhi syarat aman dan berkhasiat.

Saat ini, jenis obat non resep yang beredar dimasyarakat begitu banyak, diantaranya obat sakit kepala, obat sakit perut, obat kecantikan, obat nyeri, obat multivitamin, bahkan sampai pada penawaran obat vitalitas dan kesuburan bagi pria dan wanita. Dengan semakin banyaknya variasi obat non resep yang ditawarkan oleh industri farmasi melalui iklan di media massa dapat menyebabkan semakin banyak pula masyarakat dibuat bingung untuk memutuskan pembelian jenis obat non resep mana yang dapat dikonsumsi untuk jenis penyakit yang ringan tetapi tetap berkualitas dan murah. Selain itu, aktivitas iklan obat ditelevisi masih banyak digunakan oleh para produsen dikarenakan apabila diiklankan melalui internet, banyak masyarakat yang mengkategorikan obat tersebut sebagai obat palsu maupun obat ilegal. Untuk terkait obat palsu tentu masyarakat awam akan sulit menganali. Pada akhirnya stigma yang terbentuk yaitu iklan yang melalui media internet masih rawan sebagai channel yang menjamin kualitas produk yang aman dan terjamin, khususnya obat kesehatan. Suatu produk yang ditayangkan melalui iklan di televisi masih menjadi populer bagi produsen dalam rangka meraup keuntungan semata secara cepat. Demi mendapatkan keuntungan, hak konsumen pun biasanya diabaikan.

Bisnis periklanan dan industri media saling bergantung karena televisi merupakan saluran barang dagangan paling ampuh disaat ini. Dengan konsep iklan dapat menyebabkan masyarakat mau membeli produk yang tidak mereka butuhkan bahkan dengan menonton 
iklan dapat merangsang konsumen untuk mencoba produk baru atau merek baru. Pada akhirnya, iklan dapat memberikan suatu dorongan bagi masyarakat untuk berlaku konsumerisme. Adapun untuk sebaran iklan obat non resep di televisi sekarang ini menjadi hal yang penting untuk diteliti karena diasumsikan bahwa pola pemikiran masyarakat masih terpengaruh oleh terpaan pesan yang sifatnya masif dan kontinyuitas di media massa. Dan informasi lewat media massa biasanya masih dijadikan rujukan utama oleh masyarakat mengenai layak atau tidaknya suatu produk/jasa itu dimanfaatkan. Khususnya, terkait dengan kebijakan tayangan iklan obat non resep di televisi maka ada baiknya diatur oleh otoritas yang berwenang melalui desain program iklan yang bertanggungjawab, etis, unggul, serta terkait terhadap peningkatan daya saing produk obat dan makanan didalam negeri, peningkatan partisipasi publik, dan upaya debirokratisasi secara simplifikasi dan efisiensi menuju terjaminnya hak konsumen secara konstitusional di media massa.

\section{B. RUMUSAN PENELITIAN}

Berdasarkan latar belakang penelitian di atas, maka rumusan penelitian nya adalah bagaimanakah pengaruh tayangan iklan obat non resep pada televisi dengan sikap masyarakat dalam pembelian produk kesehatan industri farmasi (obat non resep)?

\section{METODE PENELITIAN}

Penelitian ini menggunakan metode survei penjelasan (explanatory survey). Untuk pengujian hipotesis dikumpulkan data dasar yang terdiri atas angket, wawancara, dan studi kepustakaan. Populasi penelitian untuk analisis ini adalah masyarakat yang berada di kota Bandung yang telah menonton tayangan iklan obat-obat non resep di televisi swasta nasional dan lokal. Dengan menggunakan teknik sampling multistage cluster maka responden yang terpilih sebanyak 400 orang berdasarkan rumus Yamane (1967: 99, dalam Rakhmat) dengan angka presisi sebesar 5\%.

\section{Analisis Data}

Dalam penelitian ini teknis analisis data yang digunakan yaitu metode statistik deskriptif dan statistik inferensial dengan jenis statistiknya adalah analisis regresi sederhana (Darmawan, 2013:165). Regresi digunakan ketika peneliti ingin memprediksi hasil atas variabel-variabel tertentu dengan menggunakan variabel lain, yang melibatkan dua buah variabel yaitu variabel bebas (independent) dan variabel terikat (dependent). Dengan kata lain, regresi sederhana mengindikasikan kepentingan relatif satu atau lebih variabel dalam memprediksi variabel lainnya. (Darmawan, 2013:179)

Analisis regresi linier sederhana adalah hubungan secara linear antara satu variabel independen (X) dengan variabel dependen (Y). Analisis ini untuk mengetahui arah hubungan antara variabel independen dengan variabel dependen apakah positif atau negatif dan untuk memprediksi nilai dari variabel dependen apabila nilai variabel independen mengalami kenaikan atau penurunan. Data yang digunakan biasanya berskala interval atau rasio.

Rumus regresi linear sederhana sebagai berikut:

$$
\mathrm{Y}^{\prime}=\mathrm{a}+\mathrm{bX}
$$

\section{Keterangan:}

$Y^{\prime}=$ Variabel dependen (nilai yang diprediksikan)

$X=$ Variabel independen

$a=$ Konstanta (nilai Y'apabila $X=0$ )

$b=$ Koefisien regresi (nilai peningkatan ataupun penurunan) 
Variabel dependen yang selanjutnya dinotasikan $\mathrm{Y}$ juga dikenal sebagai variabel tak bebas, tergantung, respon ataupun outcome, sedangkan variabel independen yang dinotasikan sebagai $\mathrm{X}$ dikenal sebagai variabel bebas, tak tergantng atau prediktor. Lebih lanjut, analisis regresi yang dapat kita terapkan dalam mencari hubungan variabel $\mathrm{X}$ dan $\mathrm{Y}$ tergantung kepada tipe dari variabel $\mathrm{Y}$ atau variabel dependen yang nilainya akan kita cari berdasarkan variabel independen dengan setidaknya dua, yaitu :

1. Jika variabel dependen merupakan data kontinu maka kita dapat menggunakan regresi linear, maupun non-linear, sedangkan

2. Jika variabel dependen merupakan data kategorikal maka kita dapat menggunakan analisis regresi logistik.

\section{Hipotesis Penelitian}

Hipotesis merupakan jawaban sementara terhadap rumusan masalah penelitian. Dikatakan sementara, karena jawaban yang diberikan baru berdasarkan pada teori yang relevan, belum didasarkan pada fakta-fakta empiris yang diperoleh melalui pengumpulan data (Sugiyono, 2007:93). Adapun hipotesis dalam penelitian ini adalah terdapat pengaruh yang positif dan signifikan antara tayangan iklan obat non resep di televisi terhadap sikap masyarakat dalam pembelian produk kesehatan industri farmasi.

\section{HASIL PENELITIAN DAN PEMBAHASAN}

\section{Hasil Penelitian}

Untuk melindungi masyarakat terhadap kemungkinan peredaran obat dan obat tradisional yang tidak memenuhi syarat akibat periklanan dan informasi yang tidak benar dan menyesatkan, dalam lampiran Permenkes 386 tahun 1994 antara lain disebutkan:

a. Iklan sediaan farmasi harus (1) objektif yaitu menyatakan hal yang benar sesuai dengan kenyataan, (2) tidak menyesatkan artinya tidak berlebihan perihal asal, sifat, kualitas, kuantitas, komposisi, kegunaan, keamanan dan batasan sebagai sediaan farmasi tertentu (obat, obat tradisional, dan kosmetika), dan (3) lengkap yaitu tidak hanya mencantumkan informasi tentang kegunaan dan cara penggunaan tetapi juga memberikan informasi tentang peringatan dan hal-hal lain yang harus diperhatian oleh pemakai.

b. Sediaan farmasi tidak boleh diiklankan dengan menggunakan rekomendasi dari suatu laboratorium, instansi pemerintah, organisasi profesi kesehatan atau kecantikan atau tenaga kesehatan. Selain itu tidak boleh diiklankan dengan menggunakan pergaan tenaga kesehatan atau yang mirip dengan itu. Iklan tidak boleh ditujukan untuk khalayak anakanak atau menampilkan anak-anak tanpa adanya supervisi orang dewasa atau memakai narasi suara anak-anak yang menganjurkan penggunaan obat. Iklan obat tidak diperankan oleh tenaga profesi kesehatan atau aktor yang berperan sebagai profesi kesehatan dan atau menggunakan setting yang beratribut profesi kesehatan dan laboratorium.

Obat yang dapat diiklankan kepada masyarakat adalah obat yang sesuai peraturan perundang-undangan yang ber-laku tergolong dalam obat bebas atau obat bebas terbatas, kecuali dinyatakan lain. Iklan obat dapat dimuat di media periklanan setelah rancangan iklan tersebut mendapat persetujuan dari 
Departemen/Kementerian Kesehatan RI. Iklan obat hendaknya dapat bermanfaat bagi masyarakat untuk pemilihan penggunaan obat bebas secara rasional. Iklan obat tidak boleh mendorong penggunaan berlebihan dan penggunaan terus menerus. Iklan obat harus mencantumkan spot peringatan perhatian sebagai berikut: BACA ATURAN PAKAI. JIKA SAKIT BERLANJUT HUBUNGI DOKTER.

\section{E. PEMBAHASAN}

\section{Analisis Regeresi Linear Sederhana}

Persamaan regresi dapat digunakan untuk melakukan prediksi seberapa tinggi nilai variabel dependen bila nilai variabel independen dimanipulasi (diubah-ubah). Analisis regresi mengindikasikan kepentingan relatif satu atau lebih variabel dalam memprediksi variabel lainnya (Darmawan, 2013:179).

\section{Uji Normalitas Data Penelitian}

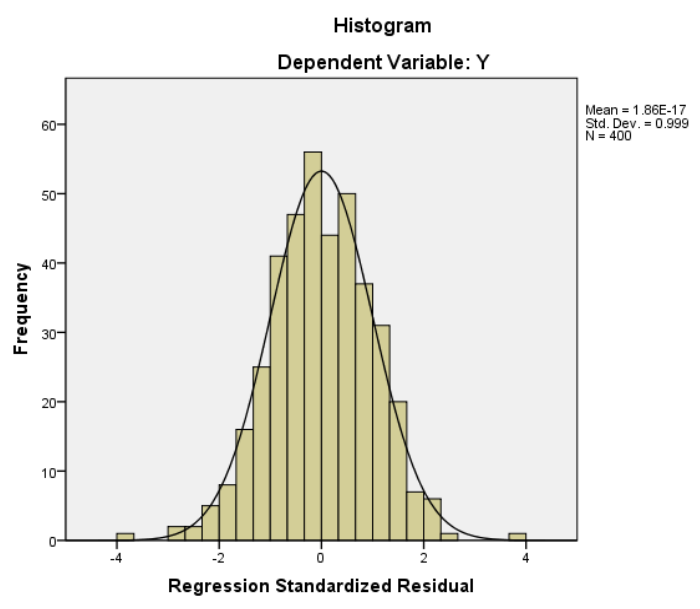

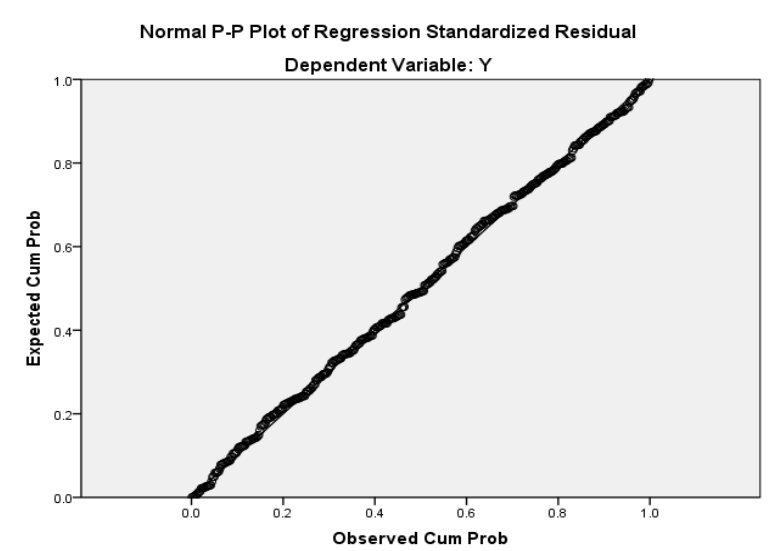

Gambar Hasil Uji Normalitas Data Penelitian

Berdasarkan Histogram di atas (gambar kiri) dapat dilihat bahwa data residualmenyebar di sekitar rata-ratanya dan membentuk kurva lonceng, selain itu diperoleh pula PP plot (gambar kanan) dimana titik-titik hampir mendekati/ tepat berada dalam garis lurus. Hal ini menunjukkan bahwa data tersebut berdistribusi normal. Untuk lebih jelasnya dapat dilihat melalui pengujian normalitas menggunakan Kolmogorov Smirnov sebagai berikut:

\begin{tabular}{|c|c|c|}
\hline \multicolumn{3}{|c|}{$\begin{array}{c}\text { Tabel } 1 \\
\text { Hasil Uji One-Sample Kolmogorov-Smirnov } \\
\text { Test }\end{array}$} \\
\hline & & $\begin{array}{l}\text { Unstandardized } \\
\text { Residual }\end{array}$ \\
\hline \multicolumn{2}{|l|}{$\mathrm{N}$} & 400 \\
\hline \multirow{2}{*}{$\begin{array}{l}\text { Normal } \\
\text { Parameters }{ }^{a, b}\end{array}$} & Mean & .0000000 \\
\hline & Std. Deviation & 5.13413435 \\
\hline \multirow{3}{*}{$\begin{array}{l}\text { Most Extreme } \\
\text { Differences }\end{array}$} & Absolute & .024 \\
\hline & Positive & .021 \\
\hline & Negative & -.024 \\
\hline \multicolumn{2}{|c|}{ Kolmogorov-Smirnov Z } & .485 \\
\hline \multicolumn{2}{|c|}{ Asymp. Sig. (2-tailed) } & .973 \\
\hline \multicolumn{3}{|c|}{$\begin{array}{l}\text { a. Test distribution is Normal. } \\
\text { b. Calculated from data. }\end{array}$} \\
\hline
\end{tabular}

berikut :

Hipotesis yang diuji adalah sebagai $H_{0} \quad$ : Data berdistribusi normal 
$H_{1} \quad$ : Data tidak berdistribusi normal

Taraf signifikan $(\alpha)=5 \%$

Kriteria Uji : Tolak $H_{0}$ jika Asymp. Sig $<\alpha$

Berdasarkan uji Kolmogorov Smirnov terlihat bahwa nilai signifikansi sebesar 0,973 lebih besar dari 0,05. Maka dapat disimpulkan bahwa data berdistribusi normal. Sehingga asumsi bahwa data berdistribusi normal terpenuhi, maka distribusi data variabel sikap masyarakat $(\mathrm{Y})$ tersebut bernilai normal.

\section{Model Regresi Linear Sederhana}

Model regresi linier sederhana yang akan dibentuk adalah sebagai berikut:

$$
\mathrm{Y}=\alpha+\beta_{1} \mathrm{X}_{1}
$$

\section{Dimana :}

$$
\begin{aligned}
Y= & \text { Sikap Masyarakat Dalam Pembelian } \\
& \text { Obat Non Resep } \\
X_{1}= & \text { Terpaan Program Iklan Obat Non Resep } \\
& \text { Pada Televisi } \\
\beta_{1}= & \text { Koefisien regresi } \\
e= & \text { Kesalahan baku }
\end{aligned}
$$

\begin{tabular}{|c|c|c|c|c|c|c|}
\hline \multicolumn{7}{|c|}{$\begin{array}{l}\text { Hasil Uji Regresi Linear Sederhana } \\
\text { Coefficients*) }\end{array}$} \\
\hline & \multirow{2}{*}{$\begin{array}{c}\text { Model } \\
\text { B }\end{array}$} & \multicolumn{2}{|c|}{$\begin{array}{l}\text { Unstandardized } \\
\text { Coefficients }\end{array}$} & \multirow[t]{2}{*}{$\begin{array}{c}\text { Standardized } \\
\text { Coefficients }\end{array}$} & \multirow[t]{2}{*}{$t$} & \multirow[t]{2}{*}{ Sig. } \\
\hline & & $\begin{array}{l}\text { Std. } \\
\text { Error }\end{array}$ & Beta & & & \\
\hline \multirow[t]{2}{*}{1} & (Constant) & 8.328 & 1.456 & & 5.720 & .000 \\
\hline & $\mathrm{X} 1$ & .356 & .019 & .680 & 18.482 & .000 \\
\hline
\end{tabular}

Dengan menggunakan bantuan aplikasi program SPSS, didapat output hasil perhitungan regresi linier berganda sebagai berikut:

Berdasarkan output di atas didapat nilai kontstanta dan koefisien regresi sehingga dapat dibentuk persamaan regresi linier berganda sebagai berikut:

$$
\mathrm{Y}=8.328+0.356 \mathrm{X}_{1}+\mathrm{e}
$$

Persamaan di atas dapat diartikan sebagai berikut:

$b_{0}=8.328$ artinya jika variabel Terpaan Program Iklan Obat Non Resep Pada Televisi (XI) bernilai nol maka variabel Sikap Masyarakat Dalam Pembelian Obat Non Resep (Y) akan bernilai 8.328

\begin{tabular}{|c|c|c|c|c|c|}
\hline \multicolumn{6}{|c|}{$\begin{array}{c}\text { Tabel } 3 \\
\begin{array}{c}\text { Hasil Uji Determinasi Data Penelitian } \\
\text { Model Summary }\end{array}\end{array}$} \\
\hline Model & $R$ & $\begin{array}{c}\mathrm{R} \\
\text { Square }\end{array}$ & $\begin{array}{l}\text { Adjusted } \\
\text { R Square }\end{array}$ & $\begin{array}{l}\text { Std. Error of } \\
\text { the Estimate }\end{array}$ & $\begin{array}{l}\text { Durbin- } \\
\text { Watson }\end{array}$ \\
\hline 1 & $.680^{\mathrm{a}}$ & .462 & .461 & 5.141 & 1.504 \\
\hline \multicolumn{6}{|c|}{ a. Predictors: (Constant), X } \\
\hline
\end{tabular}

$b_{I}=1.313$ artinya jika variabel Terpaan Iklan Obat Non Resep Pada Televisi (XI) meningkat sebesar satu satuan maka Sikap Masyarakat Dalam Pembelian Obat Non Resep (Y) akan meningkat sebesar 0.356

\section{Koefisien Determinasi}

Nilai koefisien determinasi dapat dilihat dari nilai $\mathrm{R}$ square yang sebesar 0,462 . Artinya bahwa pengaruh Terpaan iklan obat non resep pada televisi (X1) terhadap sikap masyarakat dalam pembelian obat non resep (Y) sebesar $46.2 \%$, sedangkan sisanya sebesar $53.8 \%$ dipengaruhi oleh faktor lain yang tidak diamati (tidak terduga). Misalnya karena faktor program berobat gratis yang disponsori oleh suatu perusahaan farmasi yang ada di masyarakat.

Berdasarkan data dari hasil penelitian tersebut diatas, maka dapat disimpulkan bahwa terpaan program iklan obat non resep pada televisi terhadap sikap masyarakat dalam pembelian obat-obat non resep akan memberikan hasil yang cukup signifikan. Unsurunsur terpaan iklan yang meliputi kredibilitas komunikator, isi pesan, dan intensitas isi pesan 
sangat berpengaruh terhadap aspek kognitif, afektif, dan konatif khalayak atau masyarakat. Hal ini dikarenakan komunikator dalam tayangan iklan-iklan obat non resep berupaya memperbaiki dari sisi keahlian, daya tarik, dan keterpercayaan dengan cara selalu dilakukan evaluasi terhadap tayangan-tayangan tersebut agar dapat sesuai dengan kode etik periklanan dan kode etik kesehatan.

Komunikator dalam iklan-iklan obat non resep yang tayang di televisi dituntut untuk dapat menguasai, memahami, serta memiliki semua hal yang terkait dengan keahlian, daya tarik, dan keterpercayaan agar dapat menyampaikan dengan baik isi pesan kepada khalayaknya. Menurut Mc Croskey dalam Devito (1997:63) menyatakan bahwa orang yang lebih kompeten juga merasa diri mereka memang lebih kompeten, dan karenanya mempunyai rasa percaya diri ketimbang orang yang kompeten.

Aspek opini merupakan aspek penggerak perubahan karena informasi yang diterima menentukan perasaan dan kemauan untuk berbuat. Kredibilitas komunikator dalam iklan obat non resep adalah orang atau sekelompok orang yang menyampaikan pesan dengan tujuan untuk mempengaruhi sikap, pendapat, dan perilaku orang lain baik secara verbal maupun nonverbal. Dengan adanya pengaruh yang cukup signifikan maka dapat disimpulkan bahwa kredibilitas komunikator iklan obat non resep hampir selalu berhasil mengubah opini masyarakat mengenai obatobat yang dijual secara bebas (tanpa resep dokter).

\begin{tabular}{|c|c|}
\hline \multicolumn{2}{|c|}{$\begin{array}{c}\text { Tabel } 4 \\
\text { Pedoman Interpretasi Koefisien Korelasi }\end{array}$} \\
\hline Interval Koefisien & Tingkat Hubungan \\
\hline $\begin{array}{l}0,00-0,199 \\
0,20-0,399 \\
0,40-0,599 \\
0,60-0,799 \\
0,80-1,000\end{array}$ & $\begin{array}{c}\text { Sangat Rendah } \\
\text { Rendah } \\
\text { Sedang } \\
\text { Kuat } \\
\text { Sangat Kuat }\end{array}$ \\
\hline
\end{tabular}

\begin{tabular}{|l|l|r|r|}
\hline \multicolumn{4}{|c|}{ Tabel 5 } \\
\hline \multicolumn{4}{|c|}{ Hasil Uji Correlations } \\
\hline $\mathrm{X}$ & Pearson Correlation & \multicolumn{1}{|c|}{$\mathrm{X}$} & $\mathrm{Y}$ \\
\cline { 2 - 4 } & Sig. (2-tailed) & & $.680^{* *}$ \\
\cline { 2 - 4 } & $\mathrm{N}$ & 400 & .000 \\
\hline $\mathrm{Y}$ & Pearson Correlation & $.680^{* *}$ & 400 \\
\cline { 2 - 4 } & Sig. (2-tailed) & .000 & 1 \\
\cline { 2 - 4 } & $\mathrm{N}$ & 400 & 400 \\
\hline$* *$ Correlation is significant at the 0.01 level (2-tailed). \\
\hline
\end{tabular}

Berdasarkan hasil perhitungan menggunakan software SPSS diatas diperoleh hasil koefisien korelasi sebesar 0.680 dengan sig. ( 2 tailed) sebesar $0.000<0.05$ yang artinya bahwa antara Terpaan Iklan Obat Non Resep Pada Televisi (X1) dan variabel Sikap Masyarakat Dalam Pembelian Obat-obat Non Resep Industri Farmasi (Y) signifikan memiliki hubungan positif yang kuat karena memiliki nilai koefisien korelasi pada rentang 0.60-0.799, dimana semakin tinggi terpaan iklan maka sikap masyarakat dalam pembelian obat non resep pun akan semakin meningkat.

Dari hasil penelitian menunjukkan, arah hubungan yang terjadi yaitu positif, semakin baik terpaan iklan obat non resep di televisi maka semakin baik hubungan sikap masyarakat terhadap keputusan pembelian produk (obat non resep) industri farmasi. Berdasarkan pedoman interpretasi korelasi, hubungan yang terjadi termasuk ke dalam 
hubungan yang kuat. Dari hasil tersebut, maka dapat disimpulkan bahwa variabel terpaan iklan obat non resep bila dihubungkan dengan variabel sikap akan memberikan hasil yang signifikan, dalam artian cukup berhasil dalam mengubah sikap masyarakat mengenai keputusan pembelian produk kesehatan industri farmasi (obat non resep).

Sesuai dengan asumsi Teori Cognitive Response dikemukakan oleh David A. Aakers dan Jhon G. Myers dalam bukunya Advertising Management (1987:255) mengemukakan bahwa adanya hubungan yang lemah antara kemampuan audience untuk mengingat isi dari suatu pesan dengan perubahan sikap audience yang sesuai dengan pesan yang disampaikan. Sikap dapat diubah dengan cara mengubah opini atau informasi yang dimiliki oleh seseorang mengenai suatu objek. Salah satunya dengan mempelajari opini atau ide-ide baru yang disampaikan oleh terpaan isi pesan yang bersifat persuasif dengan menyertakan beberapa alasan yang rasional, logis, etis, dan bertangungjawab sebagai faktor yang dapat meyakinkan khalayak (masyarakat) sehingga menerima opini atau ide-ide baru tersebut yang ada dalam penelitian yaitu ide mengenai pesan iklan obat non resep yang lebih berkualitas. Maka menurut Hovland, Janis dan Kelly dalam Tan (1981:93) menjelaskan bahwa seseorang akan menerima suatu opini atau informasi yang baru melalui tahapan perhatian, penjelasan, dan pemahaman terhadap isi pesan yang dikomunikasikan, khususnya yang melalui terpaan iklan pada televisi.

\section{F. SIMPULAN}

Berdasarkan hasil penelitian dan pembahasan maka dapat disimpulkan bahwa secara keseluruhan nilai kuantitatif antara terpaan iklan obat non resep pada televisi dengan sikap masyarakat dalam pembelian obat non resep produk kesehatan industri farmasi sebesar 46,2\%. Hal ini menunjukkan keputusan pembelian suatu produk yang dilakukan oleh masyarakat masih ada yang tergantung terhadap terpaan-terpaan iklan yang ditayangkan oleh televisi. Dan sebaiknya apabila membeli obat non resep di tempat yang resmi, maka harus kita kritisi melalui membandingkan dari referensi yang terdapat di googling atau mencari second opinion tentang obat yang akan kita beli.

\section{G DAFTAR PUSTAKA}

Aaker, David A. dan John G. Myers.(1987).Advertisinng Management.Third Edition. Prentice Hall Internasional.

Ardianto, Elvinaro, Lukiati Komala dan Siti Karlinah.(2007).Komunikasi Massa: Suatu Pengantar. (Edisi Revisi). Bandung: PT. Simbiosa Rekatama Media.

Arikunto, Suharmi.(2002).Prosedur Penelitian Suatu Pendekatan Praktek.Jakarta:Rineka Cipta.

Azwar, Saifuddin.(2009).Reliabilitas dan Validitas.Yogyakarta : Pustaka Pelajar.

Biagi, Shirley.(2010).Media/Impact:Pengantar Media Massa.(Penerjemah Mochammad Irfan dan Wulung Wira Mahendra).Jakarta: Salemba Humanika. 
Cangara, Hafied.(1998).Pengantar Ilmu Komunikasi. Jakarta: PT. Raja Grafindo Persada.

Hovland, C. Janis, Kelley. H.(1953).Communication and Persuassion.New Haven: CT. Yale University Press.

Kholid, Ahmad.(2014).Promosi Kesehatan Dengan Pendekatan Teori Perilaku, Media dan Aplikasinya.Jakarta: Raja Grafindo Persada.

Kuswandi, W.(1996).Komunikasi massa:sebuah analisis media televisi. Jakarta: Rineka Cipta.

Mar`at. (1984).Sikap Manusia, perubahan dan pengukurannya.Jakarta: Ghalia Indonesia.

Mulyana, Deddy dan Idi Subandy Ibrahim (Editor).(1997).Bercinta dengan Televisi.Bandung: PT. Rosda Karya.

Musman, Asti dan Sugeng WA.(2011).Marketing Media Penyiaran: Bukan Sekedar Jual Kecap. Yogyakarta: Cahaya Atma Pustaka.

Newhagen, J. E.(1997). The Role of Feedback in The Asseeement of News. Information Processing \& Management, 33 (5), 583-594.

Rakhmat, Jalaluddin. (1996). Psikologi Komunikasi.Bandung: Rosda Karya. .(2002).Metode Penelitian Komunikasi. Bandung: Rosda Karya.

Sugiyono. (2007). Metode Penelitian Bisnis. Bandung: Alfabeta (2013). Metode Penelitian Kombinasi (Mixed Methods). Bandung: Alfabeta.

Sutisna.(2001).Perilaku Konsumen \& Komunikasi Pemasaran. Bandung: PT. Remaja Rosda Karya.

Tan, Alexis.(1981).Mass Communications Theories and Research. Ohio: Grid Publising Icn. 